\title{
MISS JENNIFER HICKLING, M.C.S.P.
}

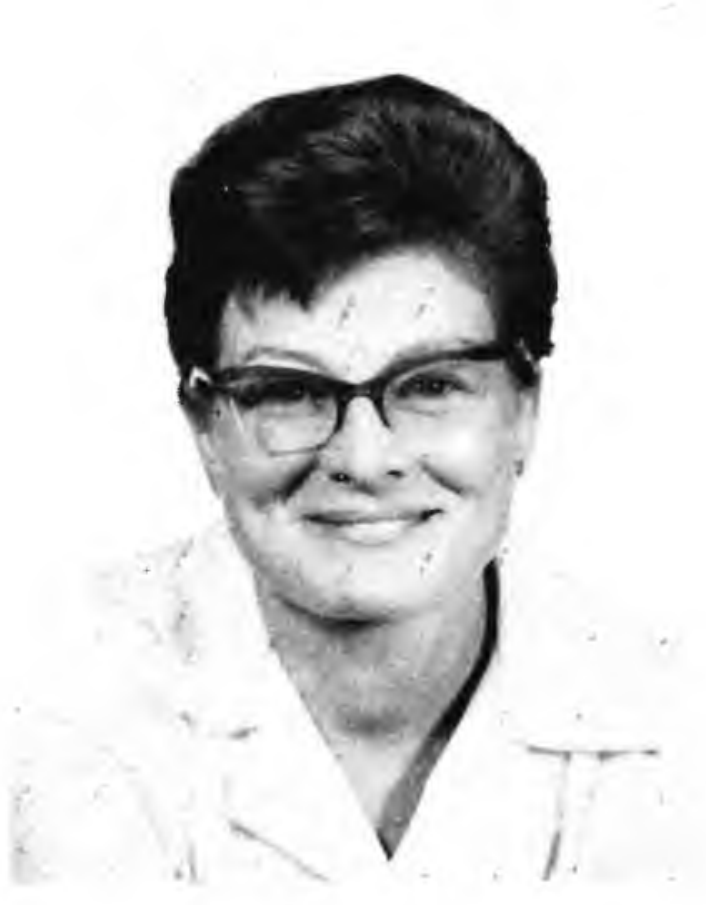

Miss Hickling has the quiet confidence of an expert in her chosen field of physiotherapy, while retaining a sincere interest in the views of others despite the fact that they may conflict with her own. These qualities, among others, enabled her to gain the confidence of her patients and the doctors and physiotherapists who worked with her or attended her courses during her brief stay in the Republic.

Jennifer Hickling was trained at St. Thomas' Hospital, London, where she first learnt the techniques of examination and treatment of soft tissues taught by Dr. James Cyriax, Physician to the Department of Physical Medicine there. After she qualified in 1948 she worked on the staff of his private clinic, and has been his senior physiotherapist since 1950. She served as a Council Member of the Chartered Society of Physiotherapy for two years.

Besides running post-graduate courses and lecturing to students in London and other parts of the United Kingdom, she has introduced her work abroad in New Zealand, France, Belgium and Holland. She has also read a paper on Manipulation at the Third Congress of the World Confederation for Physical Therapy.

With these qualifications and experience she seemed the obvious choice when negotiations were initiated to invite a physiotherapist to South Africa to teach manipulative techniques, but it was while Miss Savin was discussing this with Miss Hickling in England that it became apparent that she had the ideal personality to introduce the work here. She was subsequently approached and said that she would be delighted to come. The visit proved to be an unqualified success, for which physiotherapists in the Republic would like to express their gratitude and sincere thanks.

\section{An Appreciation by}

\author{
Dr. I. S. DE WET,
}

Senior Orthopaedic Surgeon, Pretoria Orthopaedic Hospital

It gives me pleasure to make the following statement in connection with Miss Hickling's teaching of the Cyriax techniques, which she lectured on and demonstrated during her three-month visit to Pretoria.

I have had the pleasure of attending some of her lectures and observing the techniques she adopts in manipulating the spine, including the cervical vertebrae, for certain lesions involving the paravertebral joints. The one most outstanding factor in her approach to this most difficult problemnamely that of hand, shoulder or neck pain and of lower backache with or without sciatica-is that a sincere attempt is made to approach the syndrome on a scientific and medically sound basis. No attempt is made unless the patient has been seen by a medical practitioner or an orthopaedic surgeon and reliable X-rays have been taken. Furthermore, the method of examination carried out by the physiotherapist in order to establish the exact site of the lesions to be treated is, in my opinion, a scientifically sound method and does lead to valuable information in localising the pathology.

As regards the method of manipulation, it appears to be safe and harmless. This is due to the fact that manipulation is carried out without anaesthetics, and the movements carried out are very gentle. So far no cases are on record where definite harm has been done.

The medical profession as a whole is quite aware of our shortcomings in so far as correct diagnosis or pin-pointing of the lesion in many of these cases is concerned, and therefore welcomes any individual or combined attempt to improve on our ways and means of diagnosing and treating these cases. I personally have supervised at least half-adozen cases treated by Miss Hickling, and must frankly admit that in these selected cases marked improvement and to some extent lasting improvement has resulted.

In discussing the matter with other orthopaedic surgeons in Pretoria, everybody seemed to be in agreement that this method has a definite place in the armamentarium of orthopaedic and physiotherapeutic methods of treatment, and it carries our approval as a method of treatment in selected cases.

Lastly, I might mention that lately the medical profession as well as the physiotherapists have been looking for some counter-measures to eliminate the widespread practice of lay manipulators, where treatment is given without any scientific basis and without proper examination of patients. This, we all know, is an evil that has to be eliminated. The method demonstrated by Miss Hickling seems to be a definite step forward in our attempts to eliminate unscientific and in many cases dangerous means of treating the public, who are completely ignorant as regards the real facts concerning this most difficult matter.

I would therefore strongly recommend that we carry on on the basis expounded to us by Miss Hickling, bearing in mind that proper pre-treatment examination is essential, and that manipulation should be carried out in the most gentle way. 